\title{
Interactive comment on "Technical Note: Deciphering the Hydrologic Response of Riverbeds across Changes in Recharge with Electrical Resistivity Imaging" by Weston J. Koehn
} et al.

\section{Anonymous Referee \#1}

Received and published: 16 April 2018

\section{General comment}

The study presented in this manuscript describes time-lapse electrical resistivity imaging results associated with groundwater and surface water interactions in riverbeds, via data from three monitoring sites along the Arkansas River in Western Kansas. The research goals are well defined, i.e. investigating the different types of hydrologic connection between the groundwater and surface water via interpreting electrical resistivity changes as compared to vadose zone modeling. However significant methodological issues are not addressed and/or presented in details, which lead to critical concerns 
about the time-lapse electrical resistivity imaging results. I could sum up these different concerns in the following list:

- No information on the types of electrodes used throughout the experiments is provided, especially given the unusual set up including river crossing.

- No information is given about the measurement protocols, and more specifically about the use of reciprocal measurements for assessing the measuring errors.

- No information is given on how the measuring errors have been assessed.

- There is also no information available about the parameters used for the inversions of the resistivity data, and especially on how the river water was taken into account in the inversion procedure.

- The topography is apparently not included in the inversion despite clearly visible slopes in the field pictures. Not including the topography could lead to artifacts in the resistivity image...

- There is also no explanations on the way temperature changes have been corrected despite the great impact they can induce on the resistivity of the subsurface, as it is well described for example in Brunet et al. (2010).

- Presenting the changes in resistivity (in Fig. 4, Fig 5. and Fig. 6) as absolute changes of resistivity without showing the background resistivity image is definitely not the best option as clearly explained in the review of Samouëlian et al. (2005). A variation of $10 \mathrm{Ohm} . \mathrm{m}$ within a $4000 \mathrm{Ohm} . \mathrm{m}$ area is not exactly similar to a variation of $10 \mathrm{Ohm} . \mathrm{m}$ within a $50 \mathrm{Ohm} . \mathrm{m}$ area... Moreover, given that no information is given about the error level of the measured voltages, which informs on the signal to noise ratio, this is hard to tell if such small variations of resistivity are actually interpretable...

Printer-friendly version

Therefore, the interpretations of the changes in resistivity presented in the manuscript cannot really be trusted with a reasonable level of confidence. I also doubt that the chosen format (i.e. Technical Note) is relevant for presenting these results as this 
manuscript does not present significant advances or novel experimental techniques. Imaging hydrological processes with time-lapse electrical resistivity imaging has already been addressed by several publications, including HESS papers, for the last 10 years. In summary, this paper has interesting goals and the electrical resistivity imaging techniques is an appropriate choice for addressing the associated scientific questions. However critical concerns are raised about the methodology applied for processing the data and visualizing the resistivity results. In my opinion, a significant amount of detailed information is still required for publishing this study. I would recommend a major revision of this manuscript, starting by better explaining the methodology used for producing the resistivity results. This will also most probably require from the authors an additional processing of the resistivity data to include at least the topography and corrections for temperature variations.

\section{Specific comments}

Introduction: The goals of the research are well presented, but some state of the art papers are missing. These include for example Binley et al. (2015), Chambers et al. (2014), Descloitres et al. (2008), Uhlemann et al. (2016), which could help the authors in exploring approaches for better presenting their results.

Figure 2: There is a $(A)$ in the caption but no $(B)$, while there is no $(A)$ nor $(B)$ in the figure. Including a view at the continental scale in the top left corner of the left subfigure could be more convenient. The font size of the legend in the bottom left corner is too small.

Figure 3: Linear interpolations between borehole logs are probably not the best ways to draw a geologic cross-section. Also, B and B' seem flipped compared to Figure 2 or the $x$ axis has to be flipped in the right side of Figure 3.

Page 5: the interpreted changes in resistivity for the Hartland site or the Lakin site are generally very small: 10 to $20 \mathrm{Ohm} . \mathrm{m}$ (line 4), 1 Ohm.m to $10 \mathrm{Ohm} . \mathrm{m}$ (line 5), 5 Ohm.m (line 14). These can be attributed either to artifacts from the inversion, noise

Printer-friendly version

Discussion paper
Interactive comment 
in the measured voltage or temperature variations instead of actual changes in soil moisture content. Presenting changes in resistivity as resistivity ratios as it is generally the case in other studies would be much more convenient to evaluate whether this changes mean anything related to hydrological processes.

Figure 5: the changes in resistivity interpreted as recharge zones are so small that they could be associated to anything else than actual recharge... No topography is included in the resistivity model while slopes are clearly visible at the river banks in pictures in $(A)$ and $(B)$.

Page 5 line 8: "The ERI does not reveal soil heterogeneity in the profile". I would like to trust you but it would be easier if the resistivity of each site was shown in the figures.

Page 6 \& 7: The changes in resistivity measured at the Hollocomb site are larger than for the other sites which make them more reliable, even if the lack of information concerning how the temperature change was taken into account is still problematic for initiating further interpretations. Discussing why these changes in resistivity are larger than for other sites could also be helpful to understand the different hydrological processes that the paper aims to describe.

Technical corrections

Page 5 line 7: attributed to

Caption of Figure 4: "Note that the river is to the right". To the right of the pictures or the resistivity model?

Page 7 line 6: the depth to the water table

References: Binley, A., Hubbard, S. S., Huisman, J. A., Revil, A., Robinson, D. A., Singha, K. and Slater, L. D.: The emergence of hydrogeophysics for improved understanding of subsurface processes over multiple scales: The Emergence of Hydrogeophysics, Water Resources Research, 51(6), 3837-3866, doi:10.1002/2015WR017016, 2015.

Printer-friendly version

Discussion paper
Interactive

comment 
Chambers, J. E., Wilkinson, P. B., Uhlemann, S., Sorensen, J. P. R., Roberts, C., Newell, A. J., Ward, W. O. C., Binley, A., Williams, P. J., Gooddy, D. C., Old, G. and Bai, HESSD L.: Derivation of lowland riparian wetland deposit architecture using geophysical image analysis and interface detection, Water Resources Research, 50(7), 5886-5905, doi:10.1002/2014WR015643, 2014.

Descloitres, M., Ruiz, L., Sekhar, M., Legchenko, A., Braun, J.-J., Mohan Kumar, M. S. and Subramanian, S.: Characterization of seasonal local recharge using electrical resistivity tomography and magnetic resonance sounding, Hydrological Processes, 22(3), 384-394, doi:10.1002/hyp.6608, 2008.

Brunet, P., Clément, R. and Bouvier, C.: Monitoring soil water content and deficit using Electrical Resistivity Tomography (ERT) - A case study in the Cevennes area, France, Journal of Hydrology, 380(1-2), 146-153, doi:10.1016/j.jhydrol.2009.10.032, 2010.

Samouëlian, A., Cousin, I., Tabbagh, A., Bruand, A. and Richard, G.: Electrical resistivity survey in soil science: a review, Soil and Tillage Research, 83(2), 173-193, doi:10.1016/j.still.2004.10.004, 2005.

Uhlemann, S. S., Sorensen, J. P. R., House, A. R., Wilkinson, P. B., Roberts, C., Gooddy, D. C., Binley, A. M. and Chambers, J. E.: Integrated time-lapse geoelectrical imaging of wetland hydrological processes, Water Resources Research, 52(3), 1607-1625, doi:10.1002/2015WR017932, 2016.

Interactive comment on Hydrol. Earth Syst. Sci. Discuss., https://doi.org/10.5194/hess-2018133, 2018. 